\title{
LETTERS
}

\section{Failure to monitor or prevent unintended pregnancy is the key intergenerational problem, not the pregnancy outcome}

We read with interest the article published by Liu and colleagues, ${ }^{1}$ but have three critical concerns.

First, related to the age group of interest, the authors open with a statement that is incorrect in the Canadian context: "A considerable proportion of [abortions] are among teens aged 19 years or younger." Canada has had remarkable success over the past two decades with implementing strategies to reduce teen pregnancy overall. As cited by the authors, the Canadian Institute for Health Information showed that fewer than $12 \%$ of all abortion services were provided to teens. ${ }^{2}$

Second, we were surprised that the authors did not highlight the economic determinants associated with risk for having an abortion. They observed that daughters who were born into the lowestincome quintiles at birth were more likely to have a mother who had an abortion, compared with those born to mothers in higher-income quintiles. Socioeconomic status and the ability to afford effective contraception are highly correlated with risk for unintended pregnancy. ${ }^{3}$

Finally, we were most intrigued by the authors' call for research on "the effectiveness of family-centred interventions (aimed at engaging parents) in reducing sexual behaviour and unprotected sex among teenagers." ${ }^{1}$ It is unfounded to suggest that the cause of the association they describe is known. The best research in the field would suggest the problem is not the occurrence of abortion, but failure to prevent unintended pregnancy. ${ }^{4}$ Scientific approaches aim to account for and address social determinants of health related to the risk for unintended pregnancy, particularly access to affordable, highly effective contraception. ${ }^{3}$ The United States and United Kingdom conduct sexual health population surveys to understand better the relationship between social determinants of health and pregnancy intention. Canada does not measure pregnancy intention.

Government policies, systems and services across Canada must focus on the reduction of unintended pregnancy. The first step is to create a national sexual health survey that includes questions on pregnancy intention. Until we can reliably measure unintended pregnancy and related social determinants, policies and programs to reduce the need for abortion may continue to emulate the discussion points of these authors by "taking a stab in the dark" as they hope to identify causes.

We have a responsibility as a country to help all Canadians access the methods, services and knowledge they need to avoid unintended pregnancy and thus achieve their family planning goals.

\section{Wendy V. Norman MD MHSc}

Associate professor, Canadian Institutes of Health Research/Public Health Agency of Canada Applied Public Health Chair, University of British Columbia, Vancouver, BC

\section{Sarah Munro PhD}

Postdoctoral fellow, Contraception \& Abortion Research Team, Department of Family Practice, University of British

Columbia, Vancouver, BC

- Cite as: CMAJ 2018 May 14;190:E600. doi: 10.1503/cmaj.69162

\section{References}

1. Liu N, Farrugia MM, Vigod SN, et al. Intergenerational abortion tendency between mothers and teenage daughters: a population-based cohort study. CMAJ 2018;190:E95-102.

2. Induced abortions in Canada in 2014. Ottawa: Canadian Institute for Health Information; 2015. Available: www.cihi.ca/en/induced-abortions -reported-in-canada-in-2014 (accessed 2015 June 20).

3. Parks C, Peipert JF. Eliminating health disparities in unintended pregnancy with long-acting reversible contraception (LARC). Am J Obstet Gynecol 2016;214:681-8.

4. Girlhood, not motherhood: preventing adolescent pregnancy. New York: United Nations Population Fund (UNFPA); 2015

Competing interests: Wendy Norman holds a Canadian Institutes of Health Research/Public Health Agency of Canada Applied Public Health Chair, and is supported by the Michael Smith Foundation for Health Research as a Scholar, at the University of British Columbia. The university received an educational grant from Bayer Canada Inc. in 2015 to support a postdoctoral fellow working in Dr. Norman's program of research for one year. This fellow was not involved in discussions or preparation of this letter. 